Título da exposição:

O Acampamento Farroupilha e a legitimação tradicionalismo gaúcho através de um ensaio fotográfico

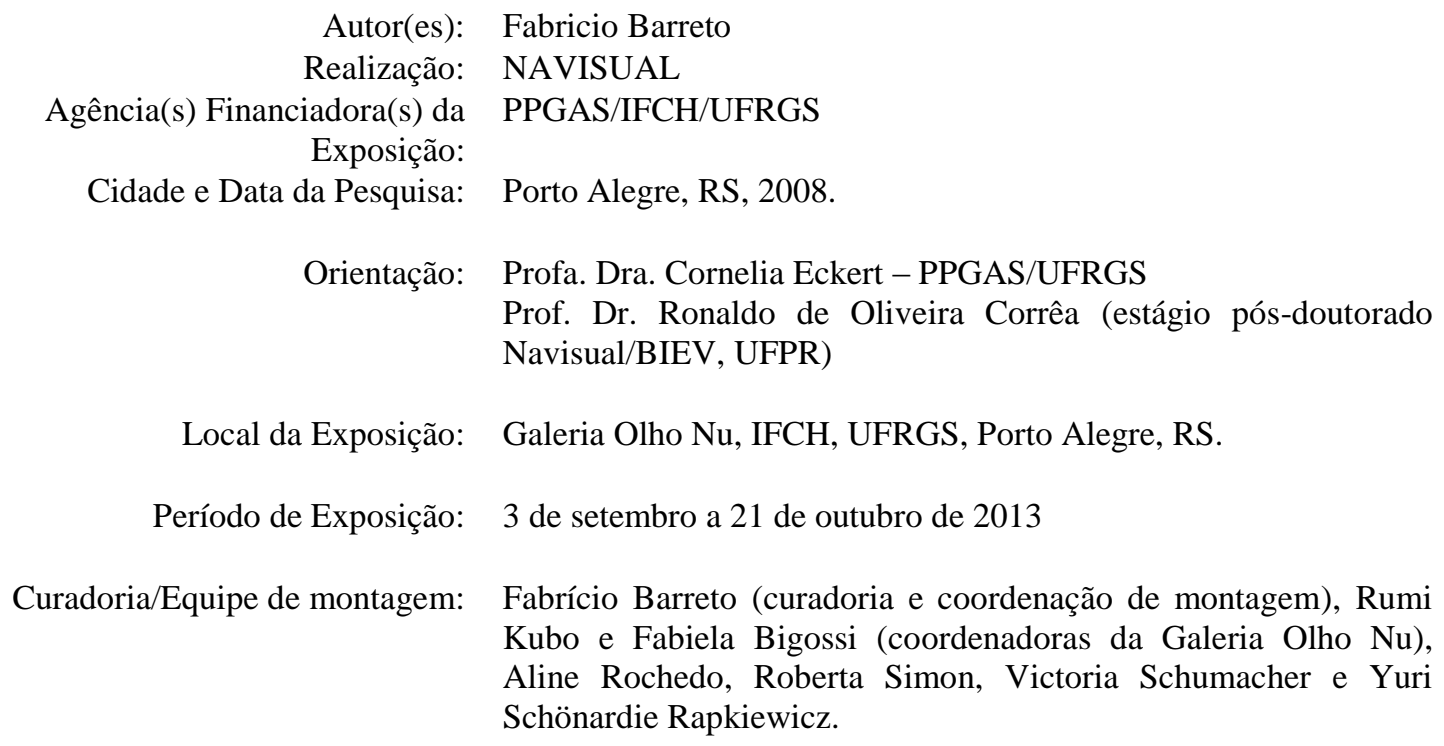

Ficha técnica: 12 imagens impressas em adesivo e coladas em PVC tamanho $35 \times 50 \mathrm{~cm}$ (3 verticais e 9 horizontais), coladas em peças de foamboard.

Câmera e lente(s) utilizada(s): câmera Canon 30D lente Canon 70-200mm f/2.8L USM

lente Canon 24-70mm f/2.8L USM lente Canon 1-22mm f/3.5-4.5 USM flash Canon $550 \mathrm{EX}$ speedlite transmiter ST-E2 (dispositivo que dispara o flash a distância através de impulso infra-vermelho)

Forma de Citação da resenha: SIMON, Roberta. Visualidades Farroupilhas. Revista Iluminuras [on line], Porto Alegre, v 15, $\mathrm{n}^{\mathrm{o}} 35$

\title{
VISUALIDADES FARROUPILHAS
}

\section{Roberta Simon $^{1}$}

\section{Apresentação}

De 03 de setembro à 21 de outubro de 2013, a Galeria Olho $\mathrm{Nu}^{2}$, na Universidade Federal do Rio Grande do Sul, exibiu a exposição de Fabricio Barreto, intitulada "O Acampamento Farroupilha e a legitimação do tradicionalismo gaúcho através de um ensaio fotográfico". Diferentemente das exposições anteriores, as 12

\footnotetext{
${ }^{1}$ Universidade Federal do Rio Grande do Sul, Brasil.

${ }^{2}$ A Galeria Olho Nu localiza-se no segundo pavimento do prédio 43322, do Instituto de Filosofia e Ciências Humanas, Campus Vale, Universidade Federal do Rio Grande do Sul, e tem por curadores pesquisadores e voluntários vinculados ao Núcleo de Antropologia Visual e da Imagem - NAVISUAL.
} 
imagens foram emolduradas sem os vidros, dispostas diretamente na parede e tiveram peças de divulgação como folder e cartaz.

Em 2008, motivado pelo grupo Baita Profissional, do qual participa, o fotógrafo voyeur registrou o Acampamento Farroupilha, que acontece no Parque Maurício Sirotsky Sobrinho (ou Parque da Harmonia), próximo ao centro de Porto Alegre/RS. Nesse evento são lembrados os "feitos" dos gaúchos na Guerra dos Farrapos (1835-1845) numa releitura construída por um imaginário do que se entende ser "gaúcho". Ocorrem palestras, espetáculos, lançamento de livros, churrascos em fogo de chão, bailes, cavalgadas, rodeios, entre outras atividades, com seu ponto alto no dia 20 de setembro, data da Proclamação da República Riograndense, durante a Guerra dos Farrapos. É um momento de culto às tradições, transcendendo o próprio Movimento Tradicionalista Gaúcho (Barreto e Jacobsen, 2013).

Esse clima de passeio pelo evento é lembrado tanto pela narrativa discursiva das imagens em exposição, quanto pelo espaço físico da galeria, pois ela se localiza no corredor, entre salas de aulas e auditório. Logo, percorrê-la exige um exercício de parar, observar um lado e o outro. A experiência estética se revela nesse percurso entre as imagens fotográficas e o imaginário. 


\section{Percurso}

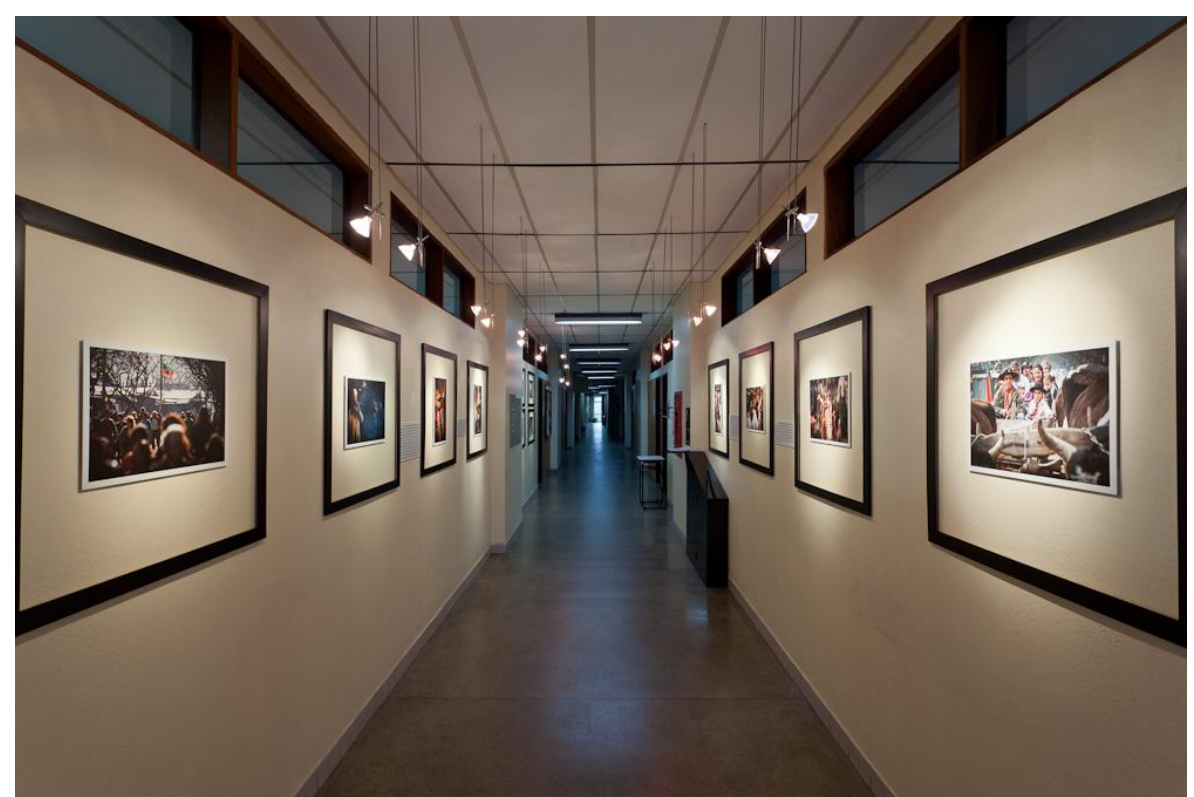

Figura 1: Vista geral da exposição "O Acampamento Farroupilha e a legitimação do tradicionalismo gaúcho através de um ensaio fotográfico" - perspectiva da entrada (foto: Fabricio Barreto)

Fabricio, junto com a equipe de pesquisa e coordenadoras da Galeria Olho $\mathrm{Nu}$, propuseram para a disposição das imagens um jogo de leituras entrecruzadas. Fotografias que dialogavam mais, pelo caráter informativo e/ou estético, foram dispostas frente a frente, uma para outra. As duas primeiras imagens da galeria, por exemplo, para quem está no fluxo em direção ao interior do prédio, apresentam e contextualizam o ambiente do acampamento. À esquerda, em plano mais aberto, a multidão sem rostos, que se confunde com o todo, caminha pelo espaço e nos convida para a mesma incursão. A bandeira do Rio Grande do Sul ocupa a parte superior central da imagem e traz o tom colorido e indicativo do espaço em que se encontra. A identidade, os corpos, os imaginários, os rituais, os dizíveis e invisíveis são contextualizados. Já percebemos por onde essas histórias vão nos levar. Os jogos de luzes nos situam em um "entre" espaços. A luz frontal da exposição faz-nos lembrar que estamos no aqui e agora, tempo presente e reflexivo sobre as imagens; enquanto que a contraluz que surge do fundo da fotografia nos chama para dentro, para um mergulho de memórias, identidades, ficções e tradições. 

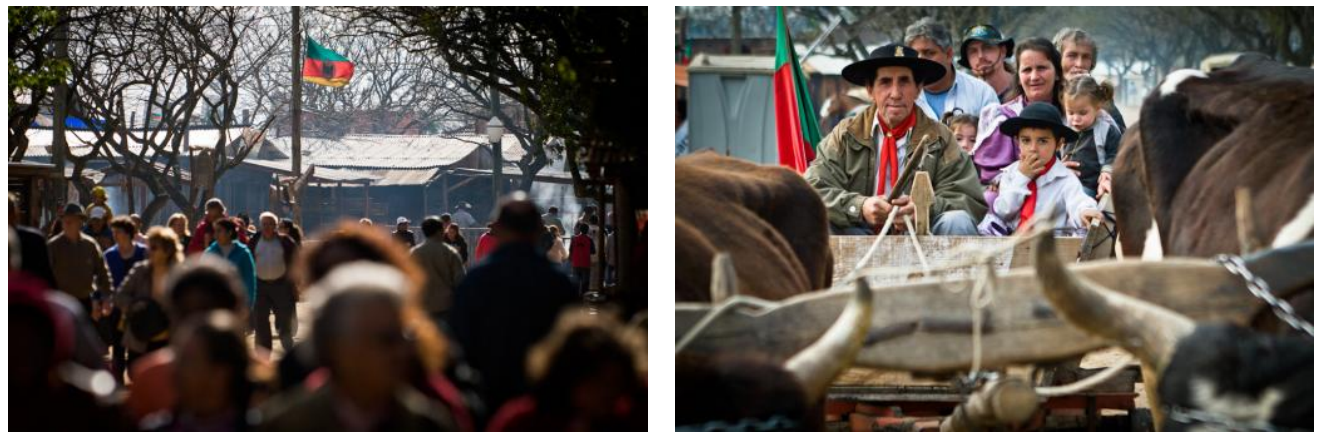

Figura 2: Primeira foto à esquerda Figura 3: Primeira foto à direita (Foto: Fabricio Barreto)

(Foto: Fabricio Barreto)

Essa incursão no ambiente apresentado pode se dar num nível superficial e nem sermos tocados pela paisagem, como se víssemos apenas uma bricolagem sequencial de cenas pelas janelas de um trem. Ou pode nos abrir um nível de contato mais intimista. A viagem interior faz eclodir memórias do passado, misturadas com a uma identidade e questionamentos do presente. Que sentimento de identidade é esse? Nesses entrelaçamentos de imagens e realidades, não estaríamos nos confrontando com a ideia

de uma identidade originária a reencontrar, de uma originalidade a preservar, de uma verdade a atingir? A fantasia de um 'autêntico' (genuíno), acompanha nossos passos, como, certamente, acompanhou os passos de Winnicott ao elaborar o conceito de falso-self. (Berry, 1991: 102)

O "entre" nos propicia uma relação dinâmica, constante, contínua e fluida de não oposição entre realidade e ficção, entre o autêntico e o falso, entre o outro e o nós, entre a imagem impressa e o imaginário, entre o pertencer e o não-pertencer, entre o orgulho e o embaraço. Símbolos tão emblemáticos como uma bandeira ou as roupas típicas de um grupo em uma charrete, fazem realçar reflexões pessoais e coletivas sobre identidade.

Quem são os gaúchos? Qual a minha relação com os gaúchos? O que penso sobre os gaúchos? Os questionamentos diante das imagens podem levar a conexões reminiscentes de um passado que reverberam no presente. Uns se identificam e outros se percebem estrangeiros a essa tradição, podendo sustentar uma fantasia reconfortante de fazerem parte de um todo e de um espaço universal (Berry, 1991: $125)$.

A ideia desta resenha não foi entrevistar o autor das imagens, nem seus leitores, e sim, flutuar no universo etnográfico do "entre-espaços" e dos deslocamentos 
imaginários que elas nos provocam. Assim, trazemos um sujeito ativo no processo de recepção (Jacks, 1999: 31) e imerso em elementos simbólicos culturais. Esse sujeito é influenciado por um campo social que contribui para apreensão do potencial cognitivo e estético da imagem.

Segundo Ulpiano Bezerra de Meneses, é importante neste contexto considerar "um tratamento mais abrangente da visualidade como uma dimensão importante da vida social e dos processos sociais" (Bezerra de Meneses, 2003: 11). A visualidade é um aspecto cultural que influencia os critérios de captação pelo autor-fotógrafo, de organização e de seleção para exposição das imagens. A visualidade é historicamente concebida como o conjunto de práticas e discursos associados às distintas formas de experiência visual (op. Cit: 31). Pelas visualidades cruzamos os aspectos sensíveis e interpretativos dessas imagens.

\section{Visualidades}

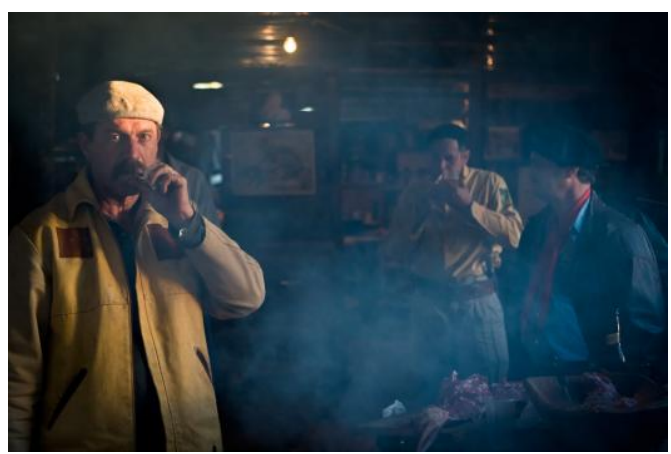

Figura 3: Segunda foto à esquerda (Foto: Fabricio Barreto)

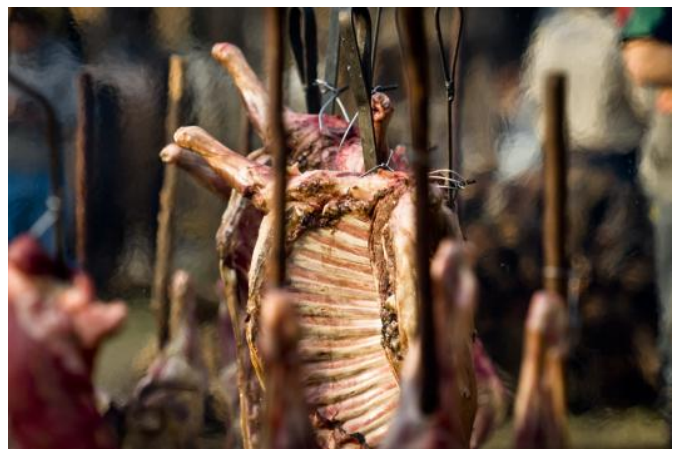

Figura 4: Segunda foto à direita (Reprodução: Roberta Simon)

No regime da visibilidade, adentramos mais além das materialidades e concretudes dos objetos. A imagem como um artefato que provoca comportamentos e não apenas carrega puros conteúdos, conforme Elizabeth Edwards (apud: Bezerra de Meneses, 2003: 30). A visualidade reside na exposição sensível do invisível, do banal, do detalhe cotidiano e da abertura estética para a experiência artística. A própria imagem é um fenômeno social que conecta sociedade e arte, que transmite experiências do saber prático e plural, provocando esforços de deslocamentos temporais e espaciais. Ela cria fluxos discursivos pelas articulações, mediações e formações de novas possibilidades narrativas experimentadas pelo público ativo. 
Assim, é pela interpretação que o sentido da obra se constrói, relativizando um passado - não o passado cronológico, fossilizado e morto -, mas um passado permanentemente em reconstrução. Essas flutuações e movimentos da história se dão pelos diferentes pontos de vista e horizontes que se cruzam no momento de visitação à exposição. Ver é ter horizontes, mesmo que delimitado. Tanto os nossos horizontes, quanto as nossas interpretações são delimitadas - essa é a regra do jogo, segundo Gadamer (1998).

Uma poética da tradição surge desse jogo interpretativo. Pelas imagens esfumaçadas apresentadas acima, acionamos os sentidos táteis e efêmeros captados e eternizados pelas lentes fotográficas. As texturas das fumaças preenchem os vazios dos lugares estoicos e abrigam uma estética consagrada pela tradição gaúcha. A fumaça do tabaco compõe uma história cultural de estilo de vida, tradição milenar ligada ao descanso entre uma lida e outra, ou ao ócio, ou a uma finesse almejada. A fumaça do churrasco marca um estilo do fazer gastronômico típico da região, ratificando um imaginário que ocupa lugar central no processo de construção de identidade social.

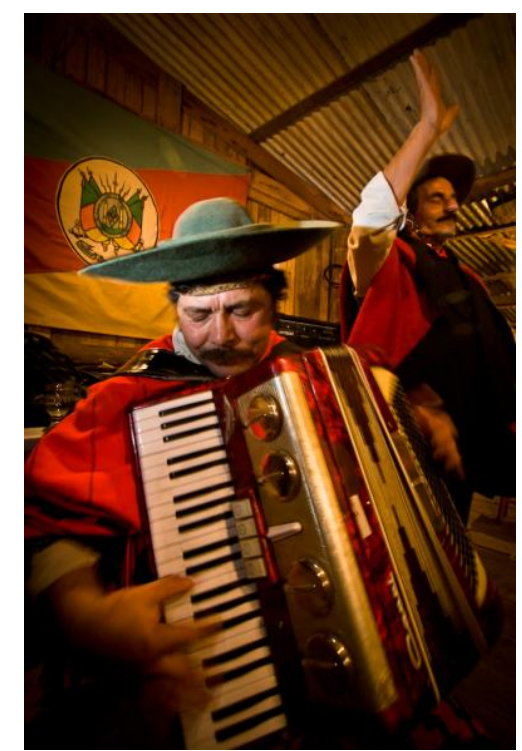

Figura 5: Terceira foto à esquerda (Foto: Fabricio Barreto)

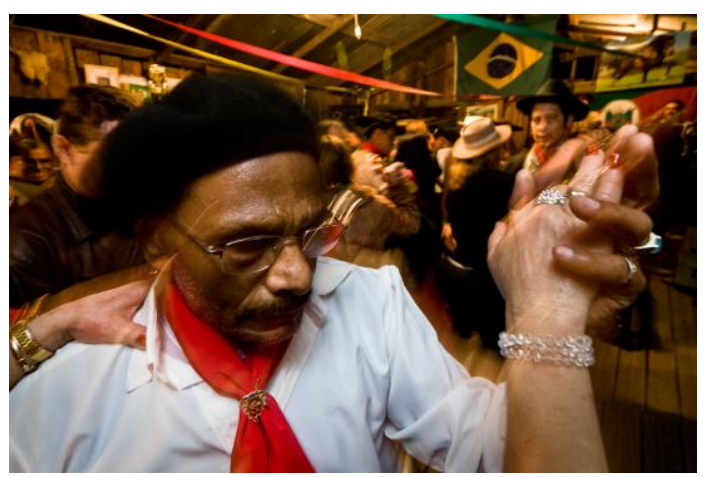

Figura 6: Terceira foto à direita (Foto: Fabricio Barreto)

Nessas imagens, o fotógrafo entra em jogo, a câmera dança junto, está bem próxima aos atores, que consentem o clique da fotografia. Como não poderia faltar num cenário de apresentações tradicionais, as performances corporais com música e dança, que reificam os símbolos da cultura gaúcha. Segundo Lévi-Strauss (1970) em 
"A eficácia simbólica”, os símbolos possuem uma função indutora dentro de um contexto específico, quando movidos pela crença desse conjunto. O gaiteiro (ou sanfoneiro, em outras regiões do Brasil) é um performer que atua na construção mítica do ritual festivo.

Quando a música começa, a experiência estética do regionalismo pode afetar corporalmente os participantes, que dançam e cantam, afirmando um compartilhamento desse sistema simbólico e fortalecendo um vínculo social. O imaginário do gaúcho é consumido e realimentado pelas práticas performatizadas durante o evento da Semana Farroupilha e no momento de contemplação das imagens na exposição. "A leitura da imagem não é nem universal nem natural: ela é antes de tudo cultural" (Conord, 2013: 26). O leitor pode se identificar, estranhar ou rejeitar as performances.

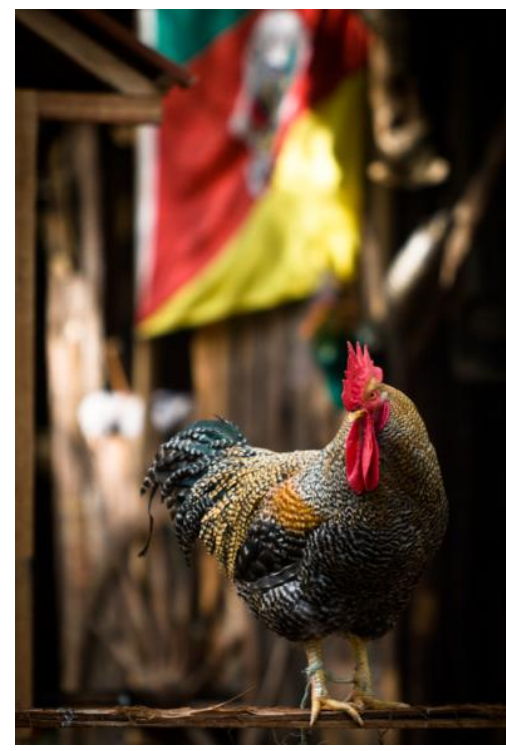

Figura 7: Quarta foto à esquerda (Foto: Fabricio Barreto)

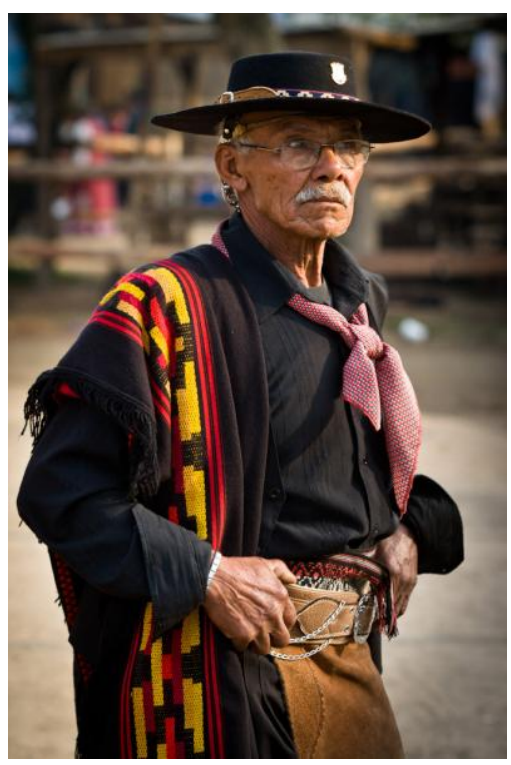

Figura 8: Quarta foto à direita (Foto: Fabricio Barreto)

A construção do imaginário gaúcho passa pela presença de elementos rústicos, voltados para o campo, os adereços e indumentárias do trabalho campestre. O cenário rural conversa com o cotidiano da metrópole. O acampamento na região central da cidade marca o encontro de culturas que se fundem, se mesclam ou se destacam. Como todo sentido é socialmente construído, um grupo contribui para estabelecer a identidade estética do outro por semelhanças ou diferenças. 
A percepção de que o sentido, sob a forma de sinais interpretáveis - sons, imagens, sentimentos, artefatos, gestos -, só passa a existir dentro dos jogos de linguagem, das comunidades discursivas, dos sistemas de referência intersubjetivos e das maneiras de construir o mundo; de que ele surge no contexto de uma interação social concreta, em que uma coisa é uma coisa para um você e um eu (Geertz, 2001: 75).

Os sentidos da tradição vão sendo criados ao mesmo tempo em que são decodificados. Quanto maior a demanda por exibição e, de certa forma, exotização, marcando as diferenças culturais, maior pode ser o orgulho e honra em apresentar tais singularidades. Em frente à câmera fotográfica o gaúcho posa para as lentes e monta um ar de masculinidade, com corpo ereto, olhar fixo à frente, o bigode grisalho marcando uma expressão firme, mãos na cintura em sentido de prontidão, chapéu com aba larga e roupa típica para a lida do campo. As encenações, diante de uma câmera fotográfica, podem ainda se intensificar. Geralmente eles fazem posturas, mostram os ornamentos, montam uma trama, um espetáculo e uma atmosfera ficcional. "Poses, uma roupa especial, arranjos de cabelo são índices importantes de como as pessoas querem que sua imagem seja vista pelos outros" (Novaes, 2012: 23).

Alinhada à masculinidade do gaúcho, a exposição apresenta em diálogo uma imagem de um galo, robusto, grande, forte, iluminado. Com tanta simbologia, o animal ganha personalidade e expressão corporal também. A trama narrativa da exposição conecta o senhor em trajes típicos gaúchos e o galo, popularmente conhecido como símbolo de masculinidade. Uma dramatização de gênero se estabelece.

A noção de masculinidade se constitui em relação ao feminino. É uma construção simbólica que não se reduz à performance de nominação que orienta e estrutura as representações corporais, mas numa transformação dos corpos. Construção prática que define as diferenças dos usos legítimos do corpo. Trata-se de uma "somatização das relações sociais de dominação" (Bourdieu, 1999: 33). Os corpos sofrem a ação da força simbólica, da "fronteira mágica" entre os dominantes e dominadas. A força masculina é muito representativa nessa cultura, tanto que a figura da mulher apareceu apenas uma vez até esta parte da exposição, junto ao grupo que se deslocava em charrete. 


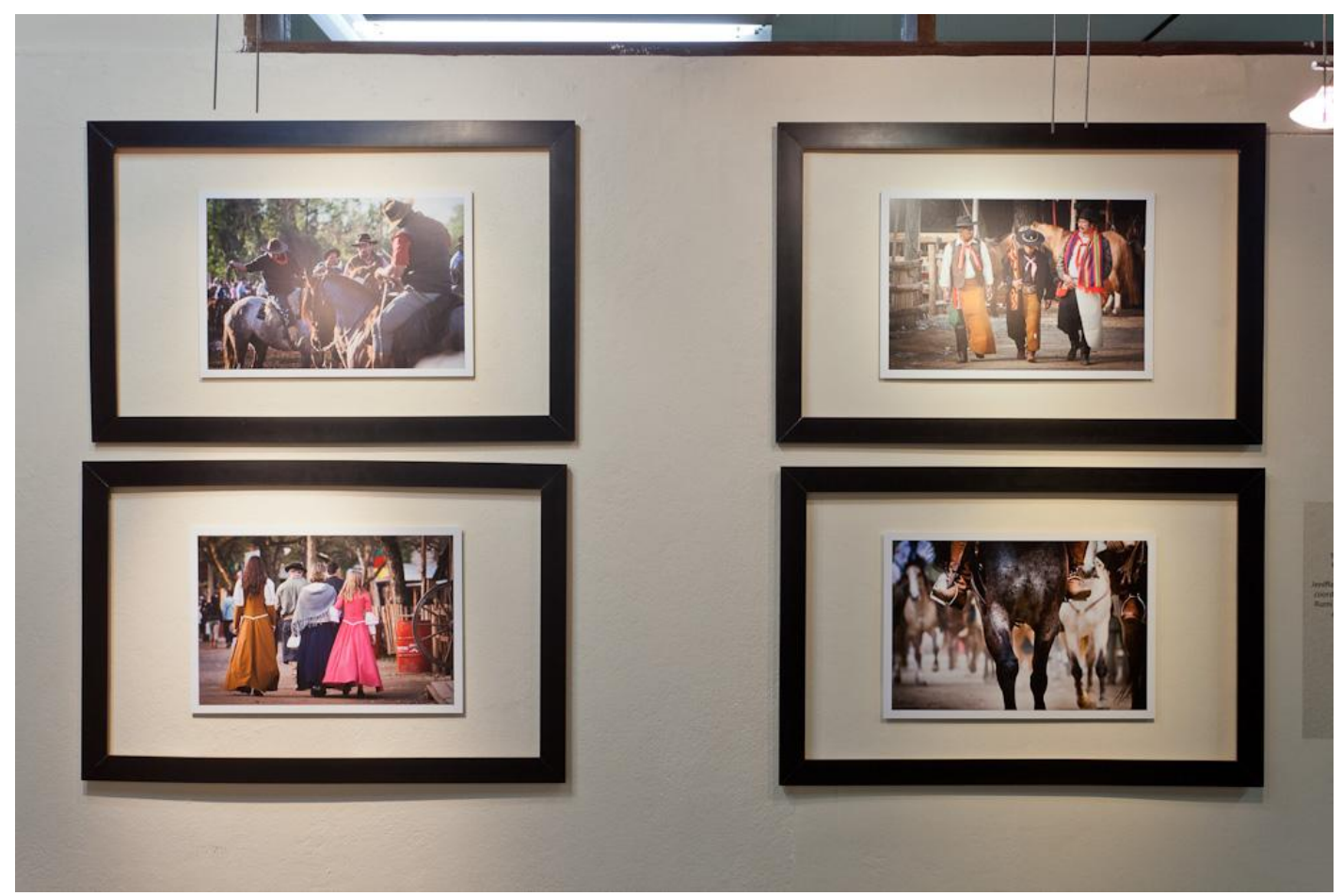

Figura 9: Conjunto de quatro imagens menores, no final da exposição, à esquerda. (Foto: Fabricio Barreto)

Os quatro quadros finais formam um painel de fechamento da visitação, com a volta de planos mais abertos, mostrando o ambiente, os coletivos e seus movimentos. Três homens numa caminhada, três mulheres em outra direção. As prendas usam vestidos longos, de mangas compridas, conforme padrões e valores sociais e morais. Os cavalos também se fazem presente nesse encerro de exposição. Eles compõem o cotidiano campeiro, elevando o gaúcho do chão, estampando uma ideia de força, energia e bravura nos deslocamentos diários.

"O que é classificado como 'tradicional' garante a ideia de uma essência e uma continuidade no tempo a distinguir as culturas", afirmou Clifford (1998; apud Gonçalves, 2007: 49). A poética da tradição apresenta seu desfecho com elementos reforçando uma "autenticidade", uma ideia de "totalidade". Aumenta o sentimento de necessidade em "resgatar" e "preservar" a tradição, segundo Clifford (op. cit). Chapéus, lenços, coletes, bombachas, botas, xales, vestidos, cela; esses são objetos que constituem parte do imaginário do "ser gaúcho". Um imaginário que se recria continuamente por imagens da memória, do cotidiano e de projeções. Percursos e visualidades de uma farroupilha em constante resignificação. 


\section{Referências:}

ACHUTTI, Luiz Eduardo Robinson. Fotografia: mediação, técnica e narração. IN:

Fotoetnografia. Um estudo de antropologia visual sobre o cotidiano, lixo e trabalho. Porto Alegre: Tomo Editorial; Palmarinca. 1997. p. 51-81.

BARRETO, Fabricio; JACOBSEN, Gabriela. Ensaio Acampamento Farroupilha e seus desdobramentos fotoantropológicos/ antropofotográficos. Texto apresentado no curso Seminário Avançado II: Análise de imagem em Antropologia Visual, do prof. Dr. Ronaldo Oliveira, UFRGS, 2013.

BERRY, Nicole. O sentimento da identidade. Trad. Maria José R. F. Coracini. São Paulo: Escuta, 1991.

BEZERRA DE MENESES, Ulpiano T. Fontes Visuais, cultura visual, história visual. Balanço provisório, proposta cautelares. IN: Revista Brasileira de História. São Paulo, v. 23, $\mathrm{n}^{\circ} 45$, pp. 11-36-2003.

BOURDIEU, Pierre. Uma imagem ampliada. In: A dominação masculina. Rio de Janeiro: Bertrand-Brasil, 1999, p. 13-67.

CONORD, Sylvaine. A função mediadora da imagem fotográfica. In: Revista Iluminuras [online]. V. 14, n. 32. 2013. ISSN 1984-1191. p. 11-29. (publicação eletrônica do Banco de Imagens e Efeitos Visuais. NUPECS/LAS/PPGAS/IFCH e ILEA/UFRGS. http://seer.ufrgs.br/iluminuras/

GADAMER. O problema da consciência histórica. Rio de Janeiro, Editora Fundação Getúlio Vargas, 1998.

GEERTZ, C. Os usos da diversidade. IN: Nova luz sobre a antropologia. RJ: Jorge Zahar Ed, 2001, pp. 68-85.

GONÇALVES, José Reginaldo Santos. Coleções, Museus e Teorias Antropológicas: reflexões sobre conhecimento etnográfico e visualidade, pp. 43 - 62. IN: Antropologia dos objetos: coleções, museus e patrimônios. Rio de Janeiro: MINC/Instituto do Patrimônio Histórico e Artístico Nacional, Departamento de Museus e Centros Culturais, 2007.

NOVAES, Silvia Cayubi. A construção de Imagens na pesquisa de campo em antropologia. In: Revista Iluminuras. V. 13, n. 31. 2012. ISSN 1984-1191. p. 11-29. (publicação eletrônica do Banco de Imagens e Efeitos Visuais NUPECS/LAS/PPGAS/IFCH e ILEA/UFRGS. http://seer.ufrgs.br/iluminuras/

LÉVI-STRAUSS, Claude. A eficácia simbólica. In: Antropologia Estrutural. Rio de Janeiro: Tempo Brasileiro, 1970, p. 204-224.

VELHO, Gilberto. Observando o Familiar. In: NUNES, Edson de Oliveira (Org). A aventura sociológica. Rio de Janeiro, Zahar, 1978. P. 36 a 46. 